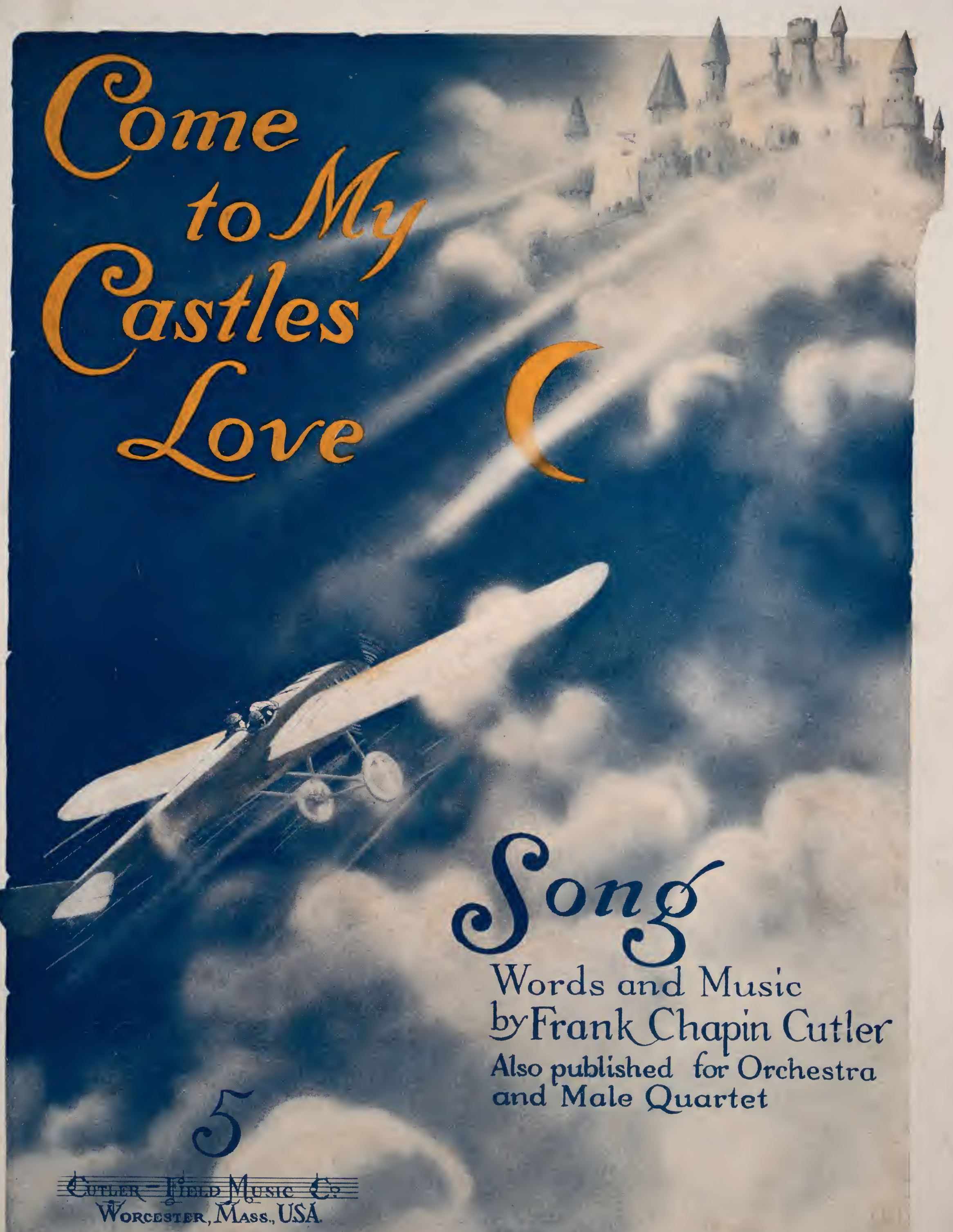



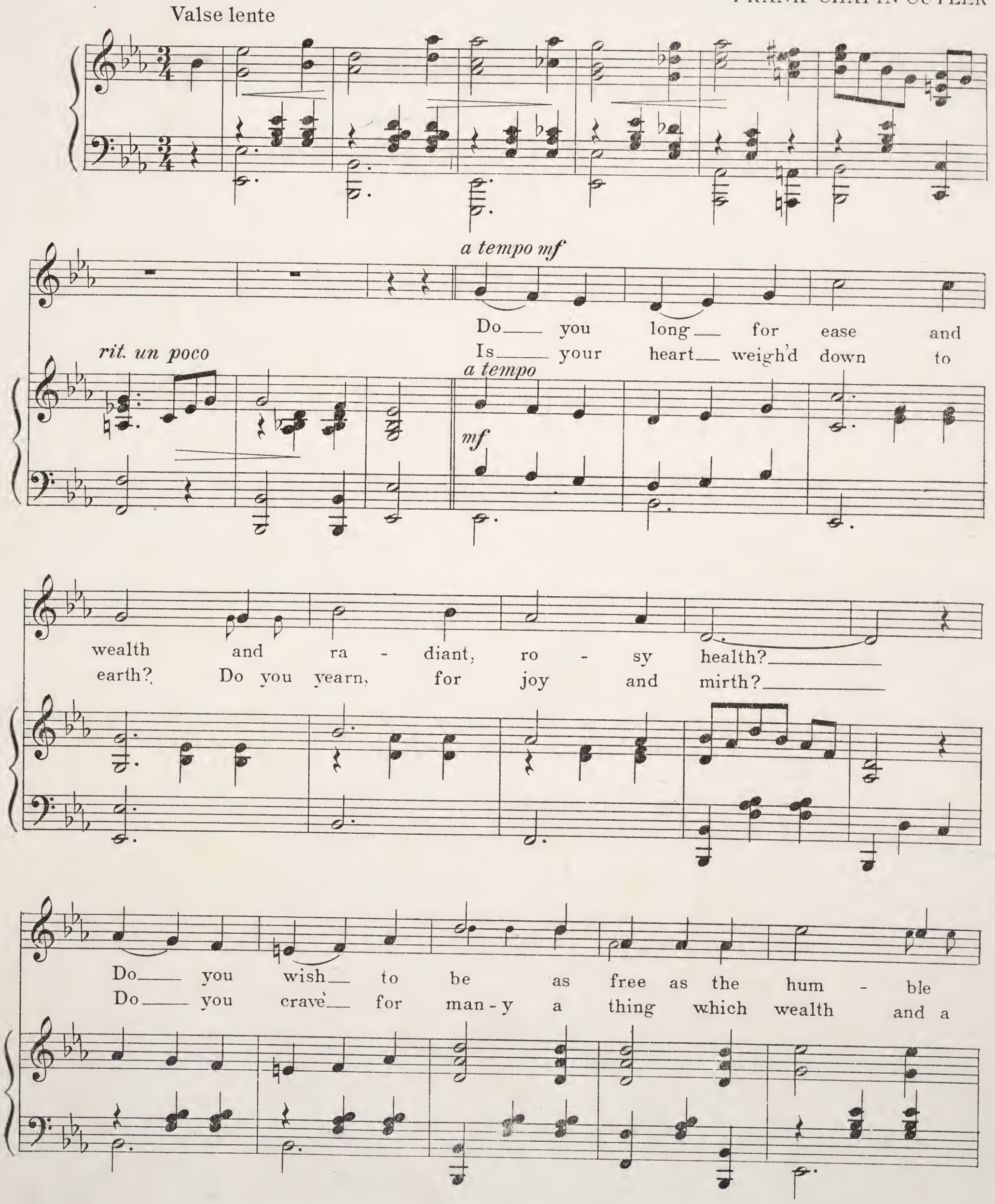

Copyright 1920 by Frank C. Cutler

International Copyright Secured All Rights Reserved 


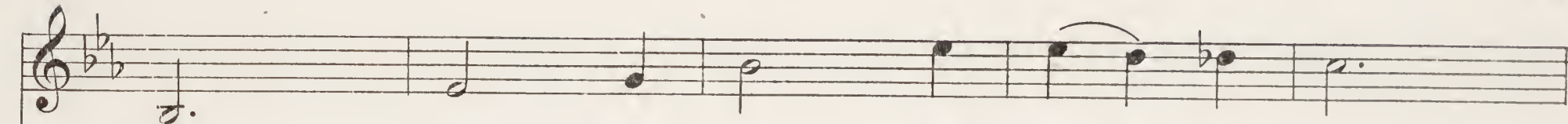

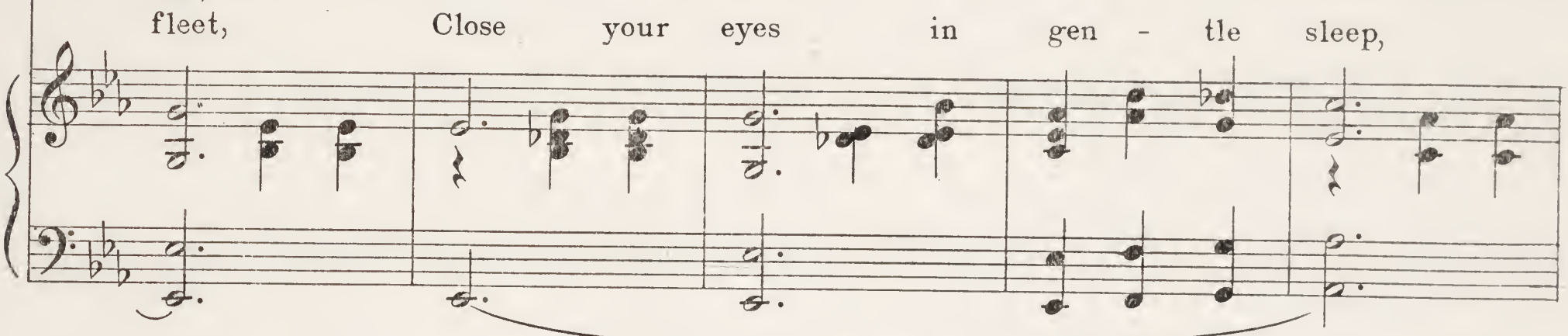

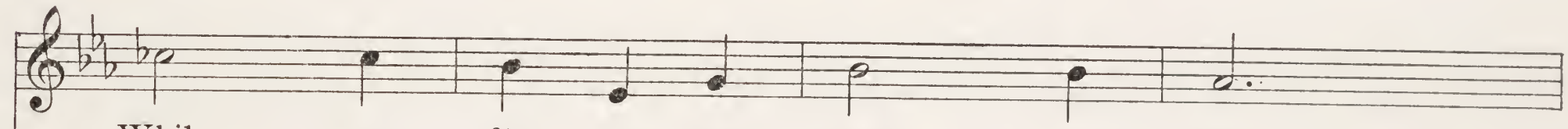
While we fly to that land so fair,

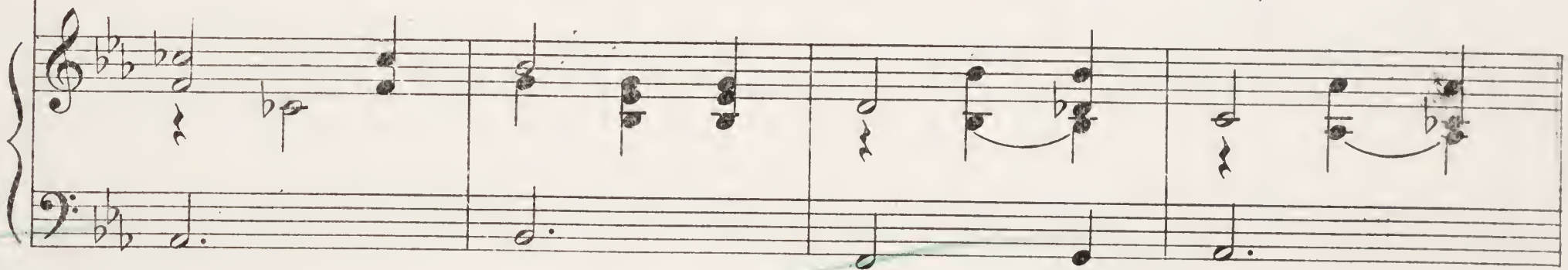

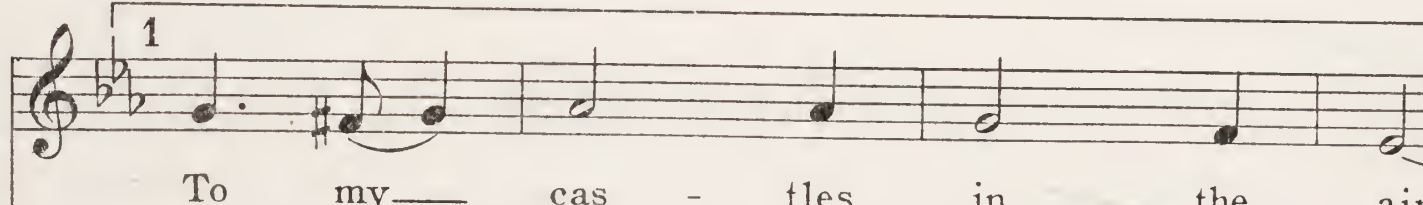

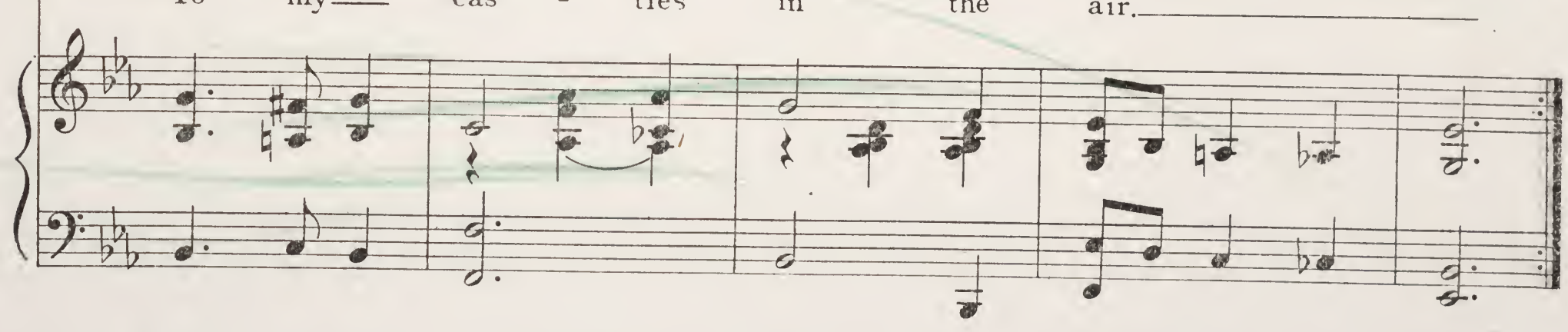

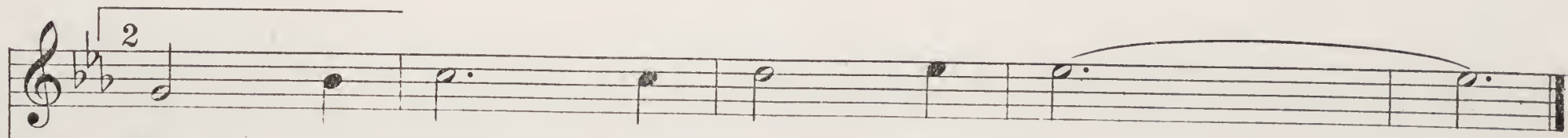

To my cas - tles in the air.

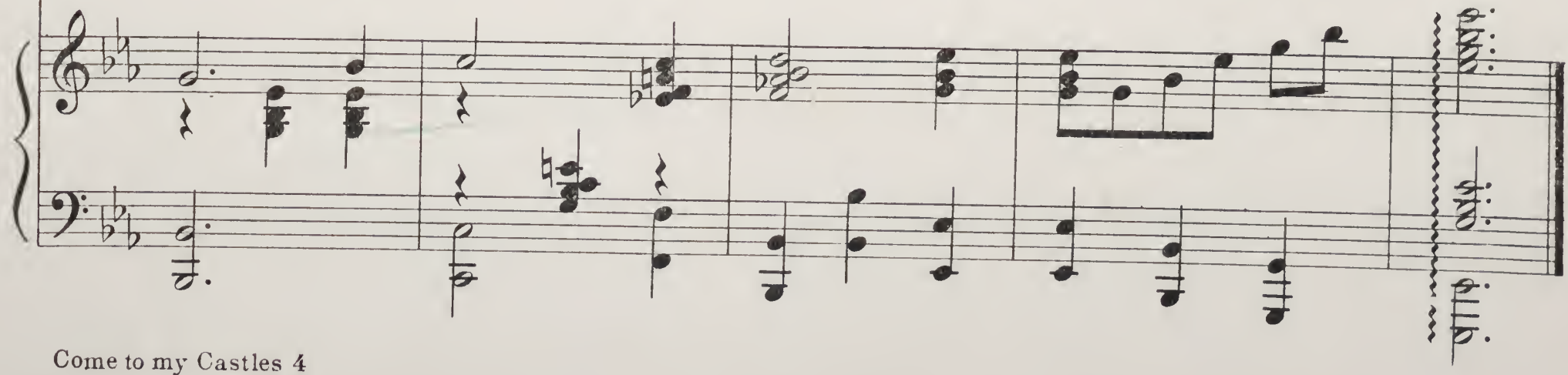




\section{LOVE'S PRAYER}

Words and Music by FRANK CHAPIN CUTLER

A charming lyric with rich and beautiful harmony.

You will find it a great success, both as a group number for professional work and equally satisfying for home en joyment.

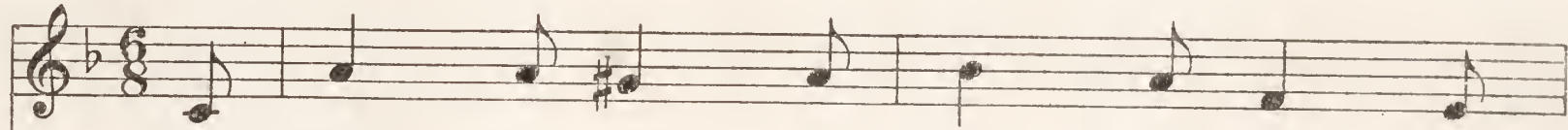

When night with such ex - qui - site charm, Its
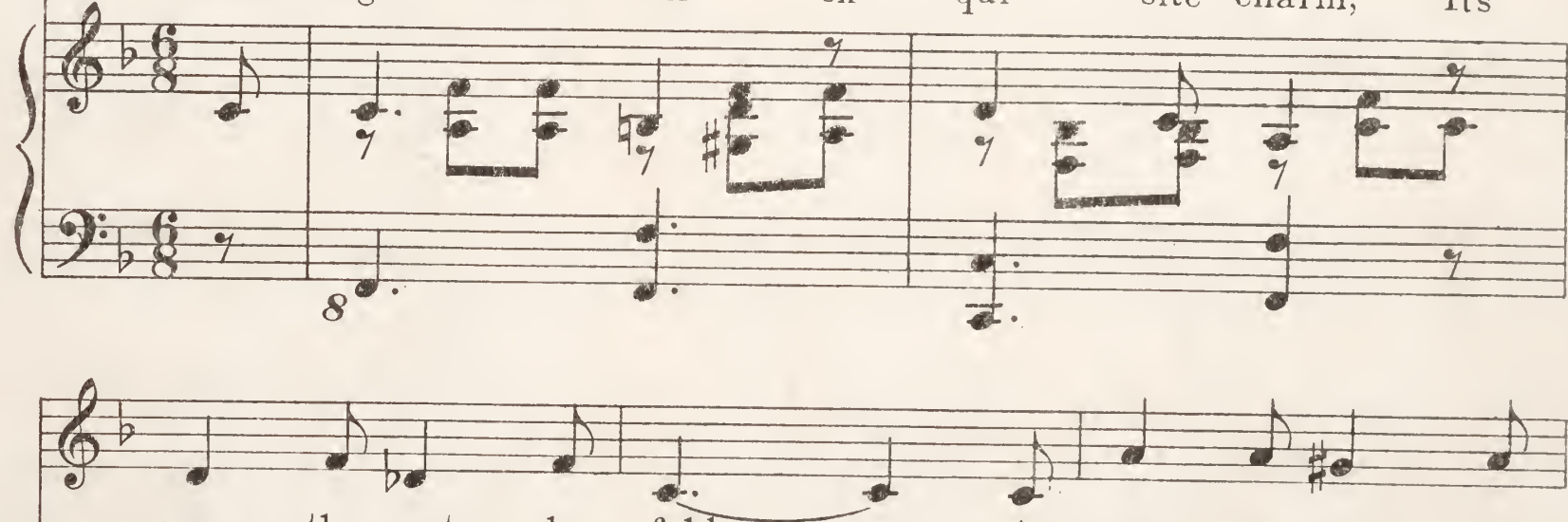
man - tle gent - ly folds_ A - round the earth and
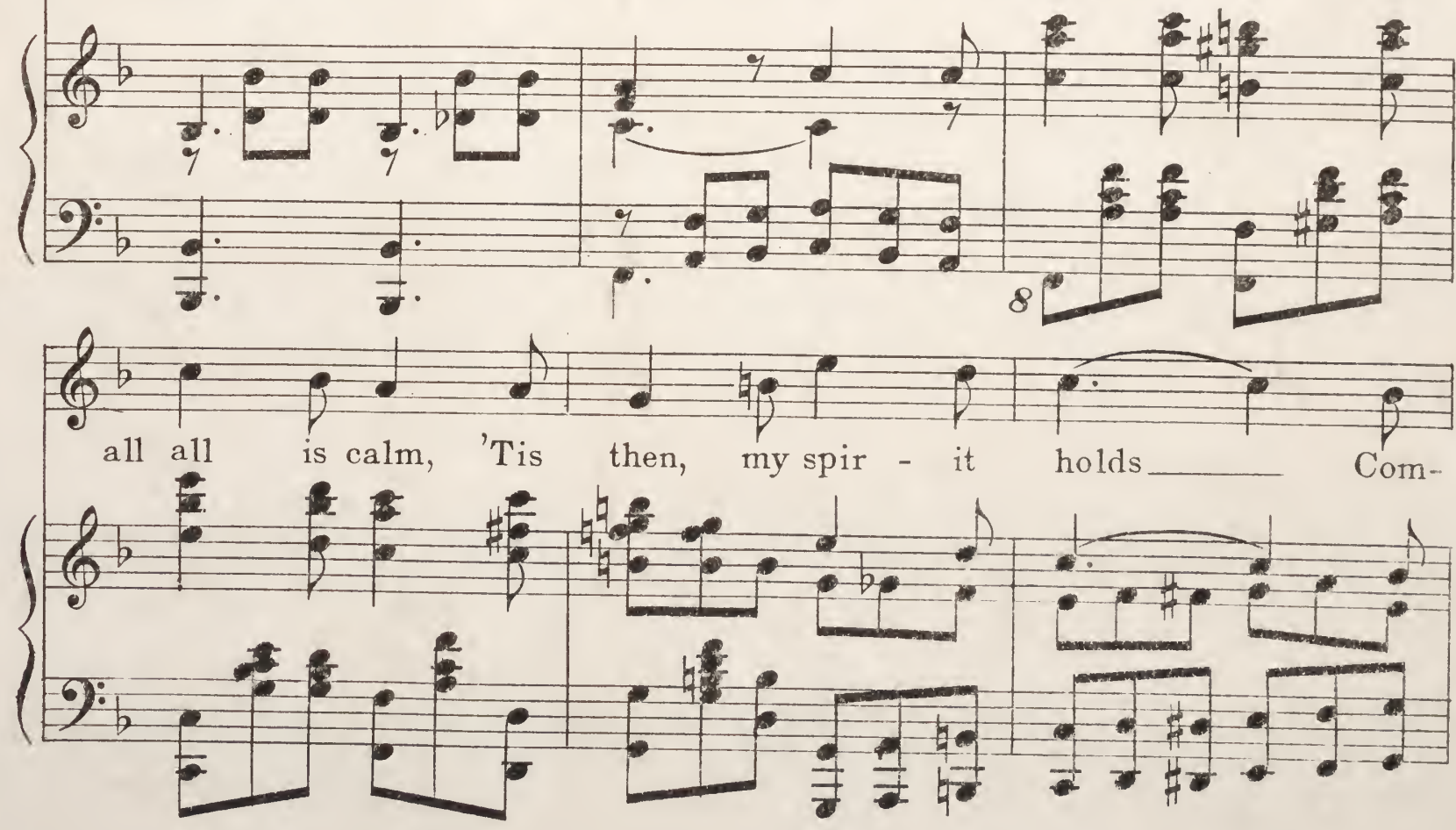

IT IS PUBLISHED WITH VIOLIN OBLIGATO 